\title{
Review \\ Nitrosamines: A review on their prevalence as emerging pollutants and potential remediation options
}

\author{
Sthembile H Mhlongo, Bhekie B Mamba* and Rui W Krause \\ University of Johannesburg, Department of Chemical Technology, PO Box 17011, Doornfontein, 2028, South Africa
}

\begin{abstract}
This review provides an overview of the current state of knowledge on the prevalence of nitrosamines in drinking water, especially nitrosodimethylamine (NDMA), and discusses published research on the detection, mechanisms of formation, and removal of nitrosamines. While the number of published reports in the South African context is very limited, this review also attempts to contextualise and report specifically on the challenges for South Africa. Besides direct industrial or human-derived contamination, nitrosodimethylamine can be formed through a chemical reaction between monochloroamine and an organic-based compound such as dimethylamine which is frequently detected in surface water. It has been suggested that chloramination of surface waters with a high concentration of dissolved organic carbon (DOC) could result in elevated NDMA formation. Growing evidence suggests that NDMA occurs more frequently and at higher concentrations in drinking water systems that practise chloramination compared to systems that use chlorination.
\end{abstract}

Keywords: drinking water, mechanisms of formation of nitrosamines, N-nitrosodimethylamine (NDMA)

\section{Introduction}

Nitrosodimethylamine (NDMA) belongs to a group of extremely toxic and mostly carcinogenic substances, the $\mathrm{N}$-nitrosamines. NDMA and other members of the group are also considered as emerging organic pollutants, since their increased presence in drinking water has been linked to both raw-water contamination and developments in disinfection techniques (CDHS, 2007). Decontamination of NDMA relies mostly on UV irradiation, but these methods are rather impractical and expensive when applied to municipal and wastewater treatment (Jobb et al., 1994).

Current research has focused primarily on techniques for the removal of the nitrogenous precursors that have been implicated in the formation of NDMA, but not on the removal of NDMA itself. These techniques are expected to result in an overall cost saving for the treatment process, with the added benefit of producing fewer DBPs. Other promising methods of treatment of either nitrosamines or their precursors include UV or sunlight photolysis, catalytic degradation, zeolite entrapment, and bioremediation.

Since NDMA is such a potent carcinogen (more potent than most trihalomethanes (THMs)) part of the current problem in dealing with its contamination and treatment is the detection of minute quantities of both the NDMA and the precursors on a continuous basis. In this regard several pre-concentration techniques coupled with chromatographic and spectroscopic analyses have been developed, but these are not yet able to offer continuous in situ monitoring.

Nitrosamines are not new contaminants; their potential carcinogenic effects have been studied for over 40 years. In 1976, for example, researchers proposed that increased levels

\footnotetext{
* To whom all correspondence should be addressed.

용 +2711 559 6516; fax: +2711 5596425 ; e-mail: bmamba@uj.ac.za

Received 20 March 2009; accepted in revised form 5 June 2009.
}

of NDMA in the air around industrialised urban centres could be responsible for higher rates of certain cancers (Shapley, 1976). Recently, in South Africa, the presence of NDMA and other nitrosamines, primarily from food and tobacco smoke, have been implicated as a possible cause of higher incidences of oesophageal cancers amongst Black populations in the former Transkei region (Sammon, 2007). Several other studies have correlated high incidences of certain cancers with high environmental availability of nitrosamines. In some cases this correlation is rather direct (as in the case of oesophageal carcinoma and cigarette smoking), while in others it is more difficult to determine (such as the link between certain cancers and the dietary change from sorghum- to maize-based beverages) (Sammon, 2007). In the latter case of a maize-based diet, among Black South African men in particular the epidemic increase in cancers begs the question of whether fungi such as Fusarium vertillioides (a common maize fungus) and their toxins could lead to increased levels of nitrosamines. The fungus could be a leading cause for the increased carcinogenesis; however, the increased levels of nitrosamines could be the root cause of the problem (Marasas et al., 1988). While there appears to be an epidemiological link between cancers and NDMA levels, a theory which is substantiated by several animal studies, it is not yet understood how nitrosamines cause cancer. Furthermore, to our knowledge no adequate human studies on the relationship between NDMA and cancer have been reported. Still, animal studies have shown that exposure to increased levels of nitrosamines (and even certain nitrogenous precursors) can lead to increased rates of cancer (IARC, 1982). Whether this is a direct result of the exposure to nitrosamines or whether nitrosamines merely increase an individual's predisposition or susceptibility to cancers is also still largely debated.

Much of the previous research around the occurrence of NDMA has focused on its presence in foods and beverages, where very often nitrites could be linked to higher levels of the contaminants and are the likely sources in vivo. Methods for reducing the risk of NDMA formation, such as the addition 
of ascorbic acid to processed meats, have been developed and regulated (Mitch et al., 2003b). However, since the occurrence of NDMA in water is a fairly recent discovery, treatment methods are less well known and much more research is needed. The current concern over NDMA in water stems from its detection at sites that appear to have no obvious source, and where its occurrence is thought to be linked to the disinfection process. Of particular concern are the strong correlations of elevated levels of NDMA with water treatment sites that use wastewater or monochloramination as part of their treatment regime (Mitch et al., 2003b). With the increasing demand for drinking water, the reuse of wastewater is likely to increase, and hence detection and removal of NDMA from water has become a priority worldwide. Alarmingly, the concentrations of nitrosamines have been shown to increase with increasing distance from such treatment plants (CDHS, 2007). This is probably linked to the presence of residual disinfectant in the water distribution system, coupled with the availability of nitrogenous compounds. In a study of 2 systems in Canada (Li et al., 2006), it was discovered that while there was little or no detectable NDMA in the source water, significant amounts were present in both the final (at the exit from the treatment plant) and distributed water. In fact, at a sampling point some distance from the treatment plant the concentration of NDMA was nearly 200 times greater than the recommended maximum for drinking water in the region.

A $2^{\text {nd }}$ point of concern highlighted by the Canadian study was the detection (for the $1^{\text {st }}$ time) of 2 new nitrosamines, namely $\mathrm{N}$-nitrosodiphenylamine (NDPhA) and N-nitrosopyrolidine (NP) in a drinking water distribution system. These pollutants were not present in the source water; hence they could certainly have been generated during the disinfection process. Although new nitrosamines are constantly being added to environmental monitoring and action lists, there is a need to detect previously undetected and even perhaps unknown nitroso-compounds, as well as a need to rethink, in some cases, the current proposals for nitrosamine formation. These research concerns must be complemented with further development of methods for the detection of nitrosamines, and of more affordable methods for their removal. There also needs to be a greater understanding of the aetiology of nitrosamineimplicated cancers. As an indication of the confusion in this area, there is no uniform agreement on acceptable levels of NDMA, even in the USA and Canada, where concerns over NDMA in water have resulted in some response for at least 5 years ( $\mathrm{Li}$ et al., 2006). There are also no uniform methods for detecting and removing nitrosamines in water, or for following their environmental fate.

\section{Sources of NDMA in water}

There are at least 4 known sources of nitrosamines and NDMA in particular. These are as follows:

- Direct industrial or human-derived contamination

- Microbial action

- Disinfection by-product formation

- 'Natural' degradation of precursors

\section{Direct industrial or human-derived formation}

Initial attention to the presence of NDMA in water came as a result of its detection in wastewater surrounding factories that manufacture or use unsymmetrical dimethylhydrazine (UDMH), particularly in rocket fuels and certain explosives
(Mitch et al., 2003b). These hydrazines are well-known sources of nitrosamines through oxidation (Scheme 1) and hence the detection of NDMA in high concentrations around these factories was not unexpected.

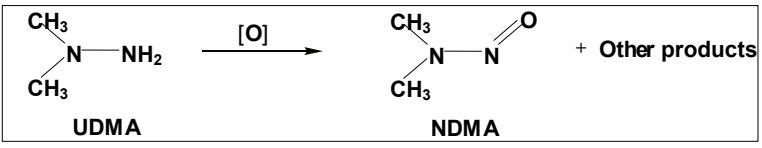

Scheme 1

Formation of NDMA from UDMA via oxidation

Unsymmetrical dimethylhydrazine (UDMA) is an important intermediate in the formation of nitrosamines, but it is by no means the only source. Indeed the nitrosation of amines by nitrosyl $(\mathrm{NO} \bullet$ ) radicals or the nitrosyl cation $(\mathrm{NO}+)$ are more likely to be responsible for the presence of NDMA in foods and in tobacco smoke (Mitch et al., 2003b). Other industrial sources such as nitrates, nitrites, rubber treatment plants, and the use of exhaust and air-drying heaters containing NOx have been well studied. For example (Sen et al., 1996) found that the use of indirect heat during the malting stage of beer-making resulted in a significant drop in the amounts of NDMA in the beer compared to the previously used method of direct air-heating with NOx-containing exhaust gases. Similarly, the formation of a nitrosyl cation is most rapid at acidic pHs (fastest cation formation at a $\mathrm{pH}$ of around 3.4 and hence controlling the $\mathrm{pH}$ can reduce the formation of nitrosyl cations (Mirvish, 1975). Another method of controlling the concentration of nitrosyl cations is the addition of reducing agents such as ascorbic acid, which can lead to the formation of neutral or more stable nitrogen species (Scheme 2). These sources of NDMA are likely to contribute to the nitrosamine load in water, and hence need serious consideration.

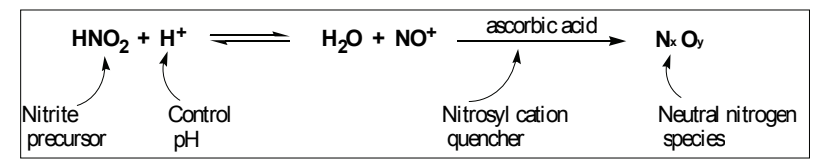

Scheme 2

Formation of nitrosyl cation and sites of action for controlling the reaction

The nitrosyl radical or cation only leads to the formation of NDMA in the presence of dimethylamine (DMA) or an amine precursor (Scheme 3), hence reducing the formation or the presence of these amines also leads to a decrease in the amount of NDMA. This is an important strategy for reducing NDMA in water.

$$
\begin{aligned}
& \mathrm{NO}^{+}+\mathrm{NH}\left(\mathrm{CH}_{3}\right)_{2} \longrightarrow \mathrm{O}=\mathrm{N}-\mathrm{N}\left(\mathrm{CH}_{3}\right)_{2}+\mathrm{H}^{+} \\
& \text {Scheme } 3 \\
& \text { Formation of NDMA in the presence of } \mathrm{NO}^{+}
\end{aligned}
$$

\section{Microbial degradation}

In the case of microbial-derived nitrosamines, the addition of antimicrobial agents to limit the formation and growth of microbes leads to a decrease in NDMA contamination. In some cases, however, the sources are difficult to control, e.g. the formation of NDMA by Candida albicans (a common yeast infection) in the mouth is thought to be responsible for some oral cancers (Krogh et al., 1978). Also NDMA formation in traditional beer, brewed from maize polluted with 
NDMA, could be responsible for the high level of oesophageal cancer in South Africa (Isaacson, 2005). While some nitrates and nitrites appear to be converted to NDMA in the stomach and by bacteria in the gastrointestinal tract, (Mirvish, 1975) to date no research has shown any significant contribution to the levels of NDMA in water from bacteria and other microbes in these environments. Similarly, since background levels of NDMA in pristine areas are very low, we could reasonably assume that natural formation pathways contribute only trace amounts of nitrosamines to the environment. Thus only direct disinfection by-products (DBPs) remain as the major source of concern for drinking-water NDMA contamination.

\section{Disinfection by-product formation}

NDMA, in addition to being a contaminant originating from rocket fuel, plasticizers, polymers, batteries and other industrial sources, has also been discovered to form DBPs in drinking water treated with chloramines or chlorine (Richardson, 2003). The use of chloramines or chlorine as a primary disinfectant may increase NDMA concentrations in drinking water treatments. Monochloramine is used directly or formed during the chlorination of drinking water in the presence of ammonia. Gerecke and Sedlak showed that the yield of NDMA from chloramination of DMA was about $0.6 \%$ in natural waters (Gerecke and Sedlak, 2003). Also, the chloramination of surface water with high DOC concentrations could result in elevated NDMA formation (Kim and Clevenger, 2007). The chlorination of drinking water results in the formation of NDMA through UDMH acting as an intermediate (Mitch and Sedlak, 2002a; Choi and Valentine, 2002). According to Mitch et al.(2003a) the rate of formation of NDMA varies with $\mathrm{pH}$, with a maximum formation rate occurring between $\mathrm{pH} 7$ and 8 . Therefore, the UDMH pathway has significant implications for disinfection of water and wastewater since NDMA formation is maximized at $\mathrm{pH}$ values of between 6 and 9, which are typical $\mathrm{pH}$ values for water and the wastewater treatment process.

In Canada and the USA, the discovery of unusually high levels of NDMA in drinking water following disinfection treatment in the late 1980s and late 1990s, respectively, prompted surveys of 145 drinking water plants in Ontario (Ministry of the Environment, 2007) and 19 in California (CDHS, 2007). These surveys indicated that NDMA concentrations at most treatment plants were below the notification levels of $9 \mathrm{ng} / \ell$ (recently changed in California to $10 \mathrm{ng} / \ell$ for NDMA and other nitrosamines), and that none were near the response levels of $100 \mathrm{ng} / \ell$. Similar results have been cited for natural aquifers, e.g. samples taken from 56 lakes in Missouri showed very little inherent NDMA but did demonstrate the potential for NDMA formation under circumstances of added DMA (Hua et al., 2007).

In contrast to these low levels in both natural and treated drinking water sources, analyses from wastewater and recycled-water plants often show much higher concentrations of NDMA. Raw sewage also often contains levels of NDMA that are 100 to 1000 times higher than recommended levels, and some of this NDMA can persist in the treated water. Studies show that treatment of these wastes and recycled waters with monochloramine or even with chlorine can result in the formation of an additional 20 to $100 \mathrm{ng} / \ell$ of NDMA (Mitch and Sedlak, 2002b). The presence of amine species such as ammonia, and DMA, can lead to significant increases in NDMA even though only chlorination is used in the disinfection train.

\section{Natural degradation of precursors}

Sources of amines can be both natural DMA and trimethylamine-N-oxide, which are both constituents of urine and human and animal waste (Zuppi et al., 1997). Artificial water treatment methods (for example, ion-exchange resins used in water treatment) can easily leach DMA and lead to increased NDMA concentrations of 20 to $50 \mathrm{ng} / \ell$ (Najm and Trussel, 2001). NDMA can be formed as a result of biological, chemical or photochemical processes (Ayanaba and Alexander, 1974). The presence of NDMA in water, air, and soil may be due to chemical reactions between ubiquitous, naturally-occurring precursors classified as nitrosatable substrates (secondary amines) or nitrosating agents (nitrites). For example, NDMA may form in air during nighttime as a result of the atmospheric reaction of DMA with nitrogen oxides (Cohen and Bachman, 1978). Soil bacteria may also synthesize NDMA from various precursor substances, such as nitrate, nitrite and amine compounds (ATSDR, 1989).

\section{Mechanisms of formation}

Current proposed mechanisms of formation of nitrosylated molecules lack detailed mechanistic research, but the available data suggest that the formation of NDMA from monochloramine (or from chlorinated nitrogenous molecules) present in feed-water probably proceeds via the UDMA pathway (Scheme 1) (Mitch et al., 2003b). Oxidation of UDMA (Scheme 4) could generate significant amounts of not only NDMA and other nitrosamines but also of other pollutants such as dimethylformamide (DMF) (Mitch et al., 2003b).

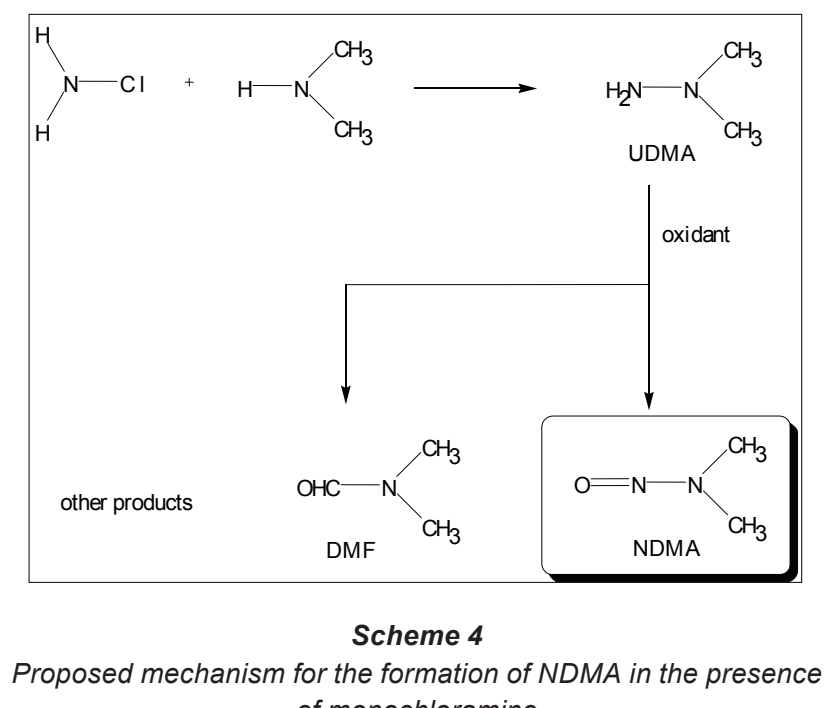
of monochloramine

Similar mechanisms have been proposed for the formation of other nitrosamines such as NP and NDPhA, and the monochloramine can serve as the source of both the reactant for the synthesis of UDMA, as shown above, and the oxidant to promote oxidation of UDMA to NDMA.

Most of these proposed methods require the presence of DMA, but even structurally-related molecules such as trimethylamine-N-oxide are potential DMA precursors and hence potential sources of NDMA. In general, however, other molecules tend to give much lower yields of NDMA due to the fact that a $\mathrm{C}-\mathrm{N}$ bond usually needs to be broken in order to release DMA. In unpolluted water the background levels of DMA are generally very low (less than $100 \mathrm{ng} / \ell$ ) but this can increase significantly 
with the reuse of wastewater or ion-exchange membranes (Richardson, 2003). Also, waters with higher dissolved organic nitrogen (DON) could lead to the formation of NDMA and other nitrosamines via nitrosation of available amines. One drawback of using this study to propose the mechanisms of formation is that they are necessarily conducted under carefully-controlled conditions. This means that the experiments do not accurately replicate conditions pertaining during the industrial chlorination of wastewater and municipal water. They do, however, provide a better understanding of the possible roles of monochloramine and the formation of nitrosamines, and as such also provide a useful 'handle' for monitoring not only the levels of NDMA, but also the potential for its formation in a system (Mitch and Sedlak, 2002a).

The use of resins and even activated carbons (ACs) may pose another risk, i.e. the catalysis of NDMA formation. While basic resins can leach amines, acid resins could be a source of displaced hydrogens, which would increase the rate of formation of nitrosyl precursors (Dietrich et al., 1986). Other potential sources of primary amines are industrial and agricultural pollutants with amine or amide functional groups, which are often formulated as amine salts to increase their solubility (IARC, 1982). Amine-based catalysts and polymers are very common in industrial processes and are often used as additives in the production of plastics and rubber. Workers in these environments and water treatment plants using these wastewaters should be particularly cautious.

\section{Regulation}

The lack of firm directives for the maximum allowable amounts of NDMA and other nitrosamines has led to rather arbitrary levels being set, and even more arbitrary enforcement of these regulations. Current internationally-accepted limits for notification are in the order of $10 \mathrm{ng} / \ell$ (Mitch et al., 2003b). This simply means that where NDMA (and a few other nitrosamines) are detected above this level the water authorities should inform regulatory bodies who would typically decide whether or not action is needed. The state of California has recently published a Public Health Guide (PHG) for levels of NDMA of only $3 \mathrm{ng} / \ell$, but again these are target levels for determining if action is needed, and in general action levels for NDMA found at source or at treatment plants are much higher - typically 10 to 30 times higher (CDHS, 2007).

The USEPA recommends that levels of NDMA in lakes and rivers should be limited to $1.4 \mathrm{ppt}(1.4 \mathrm{ng} / \ell)$, to prevent possible health effects from drinking water or eating contaminated fish (USEPA, 1980).

\section{Detection methods}

One of the major concerns in water quality management is the need to find cost-effective and appropriate methods of monitoring pollution. In the case of nitrosamines, several factors complicate this study, such as detecting sufficiently low concentrations, detecting both thermally stable and labile nitrosamines, and detecting previously unknown nitrosamines. There are several detection methods for nitrosamines that have been described comprehensively in literature especially in the chromatographic analysis compendium (Nollet and Grobb, 2006).

However, we will briefly describe two techniques which emerge as potentially useful techniques to deal with the detection of nitrosamines.

\section{Gas chromatography-mass spectrometry (GC-MS)}

This is the most common method currently in use. The USEPA for example, has Method 521 for nitrosamines in drinking water with an established laboratory approval process (USEPA, 2004). This method essentially relies on the GC-MS for detection of pollutants against internal or surrogate standards with deuterium labelling. Together with suitable pre-concentration such as solid-phase extraction (SPE), this technique has the potential to detect a large number of nitrosamines (Jenkins et al., 1995). The use of tandem MS on the other hand allows detection of unknown nitrosamines (Zhao et al., 2006). One drawback of this method, besides the high price tag for the instrument, is the fact that GC relies on thermal volatilisation and hence thermally labile nitrosamines cannot be detected. One current method to overcome this restriction is the use of liquid-chromatography (LC) in place of GC, but currently the limits of detection are a little higher (around 1 to $10 \mathrm{ng} / \ell$ ) than for GC (Mitch et al., 2003b). In response to health concerns associated with NDMA, the California Department of Health Services set an NDMA notification level of $10 \mathrm{ng} / \ell$ (CDHS, 2002).

The advantage of these techniques is that there are several possible modifications, both in the sample preparation and in the detection. For example, the addition of a gas such as ammonia can enhance the detection and lower the detection limits for most nitrosamines ( 0.1 to $10.6 \mathrm{ng} / \ell)$.

\section{Fluorescence fingerprinting}

The simultaneous collection of a matrix of excitation and emission fluorescence spectra now allows the resolution of various components of water with specific fluorescence spectra (fingerprints). While this technique cannot directly detect NDMA, there is a correlation between the fluorescence excitation emission matrix (FEEM) and the formation potential (CDHS, 2007). Currently the drawback of this method is that it relies on the detection of relatively high dissolved organic matter (DOM), in the order of at least 3 to $12 \mathrm{mg} / \ell$, which tends to have significant fluorescence excitations. The advantage may be the simultaneous determination of formation potential for other pollutants such as halomethanes.

\section{Carcinogenic potential}

Given its very low vapour pressure and low octanol/water partition coefficient, $\log$ Kow $=-0.57$ (a measure of its lipophilicity), it is unlikely to be absorbed by the skin (ATSDR, 1989). Therefore, the exposure to NDMA in the air, through showering or swimming, is considered negligible. The carcinogenic potential of NDMA is only based on oral exposure. For example, the skin permeability constant for NDMA $\left(\mathrm{Kp}=2.65 \times 10^{-4}\right.$ $\mathrm{cm} / \mathrm{h}$ ) is very low (CICADS, 2002).

Since no direct human cancer studies exist for the exposure to NDMA in water, cancer risks have been calculated based on the ingestion of about $2 \ell / d$ of contaminated water, over a lifetime. A generally accepted risk level by the USEPA is a one in a million chance of developing cancer from a life-time exposure to the chemical.

This calculation does not consider any other sources of NDMA, but provides an assessment of the 'added risk' from exposure to NDMA in water, and places the maximum exposure at between 1 and $10 \mathrm{ng} / \ell$. Although other non-cancer effects are poorly studied, this maximum level of exposure is also expected to be protective against these risks.

\section{Removing NDMA from water}

NDMA has a low vapour pressure and hence is unlikely to be adsorbed to particulates, $\mathrm{AC}$ or soil, and is therefore highly 
mobile in soil and has the potential to rapidly leach into groundwater (ATSDR, 1989). NDMA is rapidly photolysed, and would probably rapidly degrade in air or surface soil on exposure to sunlight. It has an estimated half-life of 5 to $30 \mathrm{~min}$ in the air and a few hours in surface dust and soil (ATSDR, 1989).

\section{Removal of NDMA from water by sorbents (AC and zeolites) and reverse osmosis}

In water, however, the high miscibility (NDMA has a very low Henry's constant of $2.6 \times 10^{-4} \mathrm{~atm} \cdot \mathrm{M}^{-1}$ at $20^{\circ} \mathrm{C}$ ) and low vapour pressure results in long residence times (ATSDR, 1989). This means that volatilisation from water is unlikely to occur to any great extent. The small and polar nature of NDMA means that it is poorly sorbed onto particles and ACs, but at least one recent study has shown that some zeolites or alumina-modified amorphous silica gels could be effective in its removal (Cao et al., 2007). Its small size also leads to significant amounts of NDMA leaching through reverse-osmosis membranes and therefore only about $50 \%$ is removed by this means (SteinleDarling, 2007). Also, increasing membrane fouling and other effects tend to lead to less NDMA being removed.

\section{Removal by UV radiation}

Currently the most common method of removing NDMA takes advantage of the photolytic instability of its N-N bond. NDMA has 2 absorption bands, a strong $\pi \rightarrow \pi^{*}$ band in the UV region $\left(\lambda_{\max }=228 \mathrm{~nm}\right.$, where $\left.\varepsilon=7380 \mathrm{M}^{-1} \cdot \mathrm{cm}^{-1}\right)$ and a second $\mathrm{n} \rightarrow \pi^{*}$ band at $\lambda_{\max }=332 \mathrm{~nm}\left(\varepsilon=109 \mathrm{M}^{-1} \cdot \mathrm{cm}^{-1}\right)$ (Polo and Chow, 1976; Stefan and Bolton, 2002). The most commonly-used source of $U V$ radiation in disinfection trains are the mercury lamps whose wavelength maxima do not correspond well with the absorption spectrum of NDMA. Therefore, in conditions typically encountered in drinking water disinfection a UV dose of $1 \mathrm{~J} \cdot \mathrm{cm}^{-2}$ is required to reduce NDMA concentrations by $90 \%$ (Stefan and Bolton, 2002). This is about 10 times the dosage currently used for virus disinfection by UV. Hence, while this method is theoretically feasible, it would be very expensive in drinking water treatment (Mitch et al., 2003b).

\section{Removal by sunlight photolysis}

Sunlight photolysis has also been attempted in shallow basins, but again due to poor wavelength matching and low sunlight transmission in water, approximately 1 day of exposure was required to reduce the NDMA concentration by $50 \%$ (ATSDR, 1989). Photolysis of NDMA in sunlight occurs as a result of NDMA's secondary absorption band between 300 and $350 \mathrm{~nm}$ (Mitch et al., 2003b). Atmospheric photolysis of NDMA removes NDMA from the sunlit atmosphere within a few hours (Shapley, 1976).

\section{Removal of NDMA precursors}

In contrast to NDMA, its amine precursors are chemically very different, and pose an easier target for removal (Mitch et al. 2003b). For example, amines can be removed by bio-filtration, reverse osmosis, and microfiltration. According to a study by Hwang et al. (1994), DMA and other aliphatic amines were poorly removed by sorption through the use of granular activated carbon (GAC). Although these techniques currently have very high costs, they provide a viable set of alternatives for the treatment of polluted water.

Although direct photolysis of NDMA is an effective technique, the absence of the nitroso functional group on the nitrogen-containing precursors makes the precursors unreactive. The reaction of DMA with ozone is very slow.

\section{Other removal methods}

Other techniques, such as the use of zero-valent metal ions, bioremediation, ozonation and phytoremediation, have been attempted but none have shown much success to date (Mitch et al., 2003b; Dean-Raymond and Alexander, 1976; Bingbing et al., 2009; Gui et al., 2000). In our research group we have reported the use of water-insoluble cyclodextrin polymers in the removal of various kinds of organic pollutants in water through the encapsulation of these contaminants into the cavities of the cyclodextrin moiety (Salipira, et al., 2007; Mamba et al., 2007; Mhlanga et al., 2007). These polymers have demonstrated capacity to remove the water contaminants even at parts-per-billion concentration levels and could be recycled several times while maintaining high absorption efficiencies (Salipira, et al., 2008). Recently, these cyclodextrin polyurethane polymers were applied in the removal of NDMA in distribution systems of selected water treatment plants in South Africa and the cyclodextrin polymers could remove NDMA present at ng/ $\ell$ levels (Mhlongo, 2009).

\section{Conclusions and future concerns}

This review has highlighted the current wealth of research into the occurrence, detection and treatment of NDMA in water; however, much more research is needed in some areas.

One of the concerns for pollution monitoring in general is the detection of unknown or unidentified pollutants. Very little information is available for these pollutants. As an indication of the extent of the problem, the following list shows some of the potentially carcinogenic N-nitrosoamines currently under investigation in the USA:

$\mathrm{N}$-nitrosodibutylamine, N-nitrosodimethylamine, $\mathrm{N}$-nitrosodiethylamine, $\mathrm{N}$-nitrosodiethanolamine, N-nitrosodipropylamine, N-nitrosopyrrolidine, $\mathrm{N}$-nitrosopiperidine, N-nitroso-N-methylurea, $\mathrm{N}$-nitrosomethylvinylamine, $\mathrm{N}$-nitrosomorpholine, $\mathrm{N}$-nitrosonornicotine, $\mathrm{N}$-nitrososarcosine,

$\mathrm{N}$-nitroso-N-ethylurea, and

4-(N-nitrosomethylamino)-1-(3-pyridyl)-1-butanone.

There is also a need for a study on non-carcinogenic effects; most studies have focused on the carcinogenic activity of NDMA and very few studies have been aimed at evaluating other toxic effects that may exist. High concentrations of NDMA have shown hepatotoxicity and immune system depression in animals but the toxicity at lower doses has not yet been established.

More work is required in order to understand and characterise the mechanisms of NDMA formation, including the precursors involved, the effect of residual disinfectant, the effect of ion-exchange resins, and other potential sources of DMAs.

In addition, improved and cost-effective methods for the removal of NDMA and its precursors are needed. This could involve measurements of rates of photolysis, bioremediation and phytoremediation, for which little evidence currently exists.

\section{References}

AYANABA A and ALEXANDER M (1974) Transformations of methylamines and formation of a hazardous product, dimethylnitrosamine in samples of treated sewage and lake water. J. Environ. Qual. 3 (1) 83-89. 
ATSDR (Agency for Toxic Substances and Disease Registry ) (1989) Toxicological profile for $N$-nitrosodimethylamine. US Public Health Services in collaboration with the US Environmental Protection Agency. URL: URL:http://www.atsdr.cdc.gov/toxproGiles/tp141.htm (Accessed June 2009).

BINGBING X, ZHONGLIN C, FEI Q, JIMIN S and FENGCHANG W (2009) Factors influencing the photodegradation of N- Nitrosodimethylamine in drinking water. Frontiers of Environmental Science \& Engineering in China. 3 (1) 91-97.

CALIFORNIA DEPARTMENT OF HEALTH SERVICES (CDHS) (2007) Public health goal for N- Nitrosodimethylamine in drinking water. URL:http://www.oehha.ca.gov/water/phg pdf/122206NDMAphg.pdf (Accessed June 2007).

CALIFORNIA DEPARTMENT OF HEALTH SERVICES (CDHS) (2002) NDMA in California Drinking Water URL:http://www.dhs ca.gov/water/ps/ddwem/chemicals/NDMA/history.htm/Accessed June 2009).

CAO Y, YUN ZY, ZHOU CF, ZHUANG TT, YU Q, LIU HD and ZHU JH (2007) Removal of carcinogens in environment: Adsorption and degradation of $\mathrm{N}$-nitrosonornicotine (NNN) in zeolites. Microporous Mesoporous Mater. 103 352-362.

CHOI JH and VALENTINE RL (2002) Formation of $N$-nitrosodimethylamine (NDMA) by reaction of monochloramine in a model water: A new disinfection by-product. Water Res. 36 817-824

COHEN JB and BACHMAN JD (1978) Measurement of environmental nitrosamines. IARC Sci Publ. 19 357-372.

DEAN-RAYMOND D and ALEXANDER M (1976) Plant uptake and leaching of dimethylamine. Nat. 262 394-396.

DIETRICH AM, GALLAGHER DL, DEDOSA PM, MILLINGTON DS and DIGIANO FA (1986) Enhancement of N-nitrosamine formation on granular-activated carbon from $\mathrm{N}$-methylaniline and nitrite. Environ. Sci. Technol. 20 1050-1055.

GERECKE AC and SEDLAK DL (2003) Precursors of $N$-nitrosodimethylamine (NDMA) in natural waters. Environ. Sci. Technol. 37 1331-1336

GUI L, GILLHAM RW and ODZIEMKOWSKI MS (2000) Reduction of $N$-nitrosodimethylamine with granular iron and nickelenhanced iron: 1. Pathways and kinetics. Environ. Sci. Technol. 34 3489-3494.

HUA B, VEUM K, KOIRALA A, JONES J, CLEVENGER T and DENG B (2007). Fluorescence fingerprints to monitor total trihalomethanes and $N$-nitrosodimethylamine formation potential. Environ. Chem. Lett. 5 (2) 73-77.

HWANG Y, MATSUO T, HANAKI K and SUZUKI N (1994) Removal of odorous compounds in wastewater by using activated carbon, ozonation and aerated biofilter. Water Res. 28 (11) 2309-2319.

IARC (WHO International Agency for Research on Cancer) (1982) Some $N$-nitroso compounds. IARC Monographs on the Evaluation of the Carcinogenic Risks to Humans 17 125-175.

ISAACSON C (2005) The change of the staple diet of black South Africans from sorghum to maize is the cause of the epidemic of squamous carcinoma of the oesophagus. Med. Hypotheses 64 658-660.

JENKINS SWD, KOESTER CJ, TAGUCHI VY, WANG DT, PALMENTIER JPFP and HONG KP (1995) $N$-nitrosodimethylamine in drinking water using a rapid, solid-phase extraction method. Environ. Sci. Pollut. Res. 2 (4) 207-210.

JOBB DB, HUNSINGER RB, MERESZ O and TAGUCHI V (1994) Removal of $N$-nitrosodimethylamine. Ohsweken (Six Nations) Water Supply Final Report. Ontario Ministry of Environment, Queen's Printer for Ontario.

KIM J and CLEVENGER TE (2007) Prediction of $N$-nitrosodimethylamine (NDMA) formation as a disinfection by-product. $J$. Hazardous Mater. 145 270-276.

KROGH P, HALD B and HOLMSTRUP P (1978) Possible mycological etiology of oral mucosal cancer: Catalytic potential of infecting Candida albicans and other yeasts in production of $N$-nitrosobenzylmethylamine. Carcinog. 8 1907-1912.

MAMBA BB, KRAUSE RW, MALEFETSE TJ, MHLANGA SD, SITHOLE SP, SALIPIRA KL and NXUMALO EN (2008) Removal of geosmin and 2-methylisorboneol (2-MIB) in water from Zuikerbosch Treatment Plant (Rand Water) using $\beta$-cyclodextrin polyurethanes. Water SA 33(2) 223-227.
MARASAS WF, JASKIEWICZ K, VENTER FS and VAN SCHALKWYK DJS (1988). Fusarium moniliforme contamination of maize in oesophageal cancer areas in Transkei. S. Afr. Med. J. 74 (3) $110-114$

MHLANGA SD, MAMBA BB, KRAUSE RWM and MALEFETSE TJ (2007) Removal of organic contaminants from water using nanosponge cyclodextrin polyurethanes. J. Chem. Technol.Biotechnol. 82 (4) $382-388$.

MHLONGO SH (2009) M.Sc. Dissertation, University of Johannesburg, South Africa.

MINISTRY OF THE ENVIRONMENT (1998) Drinking Water Surveillance program. URL: http://www.ene.gov.on.ca programs/3554e01.htm (Accessed June 2007).

MIRVISH SS (1975) Formation of N-nitroso compounds: Chemistry, kinetics and in vivo occurrence. Toxicol. Appl. Pharmacol. 31 325-351.

MITCH WA and SEDLAK DL (2002a) Formation of N-nitrosodimethylamine (NDMA) from dimethylamine during chlorination. Environ. Sci. Technol. 36 588-595.

MITCH WA and SEDLAK DL (2002b) Factors controlling nitrosamine formation during wastewater chlorination. Water Sci. Technol. Water Supply 2 (3) 191-198.

MITCH WA, GERECKE A and SEDLAK DL (2003a) A N-nitrosodimethylamine (NDMA) precursor analysis for chlorination of water and wastewater. Water Res. 37 3733-3741.

MITCH WA, SHARP JO, TRUSSEL RR, VALENTINE RL, ALVAREZ-COHEN L and SEDLAK DL (2003b) $N$-nitrosodimethylamine (NDMA) as a drinking water contaminant: A review. Environ. Eng. Sci. 20 (5) 389-403.

NAJM I and TRUSSEL RR (2001) NDMA formation in water and wastewater. J. AWWA February 92-99.

NOLLET LML and GROB RL (2006) Chromatographic Analysis of the Environment ( $3^{\text {rd }}$ edn.). CRC Press, New York. 419-452.

POLO J and CHOW YL (1976) Efficient photolytic degradation of nitrosamines. J. Natl. Cancer Inst. 56 (5) 997-1001.

RICHARDSON SD (2003) Disinfection by-products and other emerging contaminants in drinking water. Trends Anal. Chem. 22 (10) 666-684.

SALIPIRA KL, MAMBA BB, KRAUSE RW, MALEFETSE TJ and DURBACH SH (2007) Carbon nanotubes and cyclodextrin polymers for removing organic pollutants from water. Environ. Chem. Lett. 5 (1) 13-17.

SALIPIRA KL, KRAUSE RW, MAMBA BB, MALEFETSE TJ, CELE LM and DURBACH SH (2008) Cyclodextrin polyurethanes polymerized with multi-walled carbon nanotubes: Synthesis and characterization. Mater. Chem. Phys. 111 (2-3) 218-224.

SAMMON AM (2007) Environmental initiation is the dominant factor; tobacco or other carcinogens of low potency or concentration are sufficient for carcinogenesis in the predisposed mucosa. Med. Hypotheses 69 (1) 125-131.

SEN NP, SEAMAN SW, BERGERON C and BROUSSEAU RJ (1996) Trends in the level of $N$-nitrosodimethylamine in Canadian and imported beers. Agric. Food. Chem. 44 (6) 1498-1501.

SHAPLEY D (1976) Nitrosamines: Scientists on the trail of prime suspect in urban cancer. Sci. 191 268-270.

STEFAN MI and BOLTON JR (2002) UV direct photolysis of $N$-nitrosodimethylamine (NDMA): Kinetic and product study. Helv. Chim. Acta 85 1416-1426.

STEINLE-DARLING E, ZEDDA M, PLUMLEE MH, RIDGEWAY HF and REINHARD M (2007) $N$-nitrosodimethylamine (NDMA) removal by reverse osmosis and UV treatment and analysis via LC-MS/MS. Water Res. 42 (1-2) 347-355.

USEPA (UNITED STATES ENVIRONMENTAL PROTECTION AGENCY) (1980) Ambient water quality criteria for nitrosamines. URL: http://www.epa.gov (Accessed June 2006).

USEPA (UNITED STATES ENVIRONMENTAL PROTECTION AGENCY) (2004) Method 521 URL: http://www.epa.gov/nerlcwww/ordmeth.htm (Accessed June 2007).

ZHAO Y-Y, BOYD J, HRUDEY SE and LI X-F (2006) Characterization of new nitrosamines in drinking water using liquid chromatography and tandem mass spectrometry. Environ. Sci. Technol. 40 7636-7641.

ZUPPI C, MESSANA I, FORNI F, ROSSI C, PENNACHIETTI L, FERRARI F and GIARDINA B (1997). 1H NMR spectra of normal urines: reference ranges of the major metabolites. Clin. Chim. Acta 265 85-97. 